\title{
O Orçamento Público no Estado Constitucional Democrático e a Deficiência Crônica na Gestão das Finanças Públicas no Brasil
}

\author{
The Public Budget in the Democratic Constitutional State and Chronic \\ Deficiency in the Management of Public Finances in Brazil
}

\author{
Cláudio Ladeira de Oliveira \\ Universidade Federal de Santa Catarina, Florianópolis - SC, Brasil \\ Francisco Gilney Bezerra de Carvalho Ferreira \\ Faculdade Luciano Feijão, Sobral - CE, Brasil
}

Resumo: O presente trabalho expõe o tema do orçamento público brasileiro e a crise na gestão das finanças públicas. As reiteradas manobras de flexibilização da peça orçamentária e a constante disputa política nas relações de poder que circundam a temática acabam por frustrar o real objetivo do orçamento público no Estado Constitucional Democrático: a concretização dos direitos fundamentais. Pretende-se, ainda, neste trabalho, inserir a discussão no contexto da reforma constitucional que trouxe a inédita previsão das emendas parlamentares vinculantes no orçamento brasileiro. A pesquisa é realizada com a aplicação da técnica de investigação bibliográfica, utilizando-se o método de abordagem crítico indutivo e a avaliação qualitativa.

Palavras-Chave: Direitos Fundamentais. Orçamento Público. Emendas Parlamentares.
Abstract: This paper exposes the theme of the public budget and the crisis in public finance management. Repeated easing maneuvers budget part and constant political wrangling in the power relations that surround the theme end up frustrating the real purpose of the public budget in the democratic constitutional state: the realization of fundamental rights. It is important to insert the discussion in the context of the constitutional reform that brought the unprecedented prediction of binding parliamentary amendments in the brazilian budget. The search is performed with the application of bibliographic research technique, using the critical inductive method of approach and qualitative data evaluation.

Keywords: Fundamental Rights. Public Budget. Parliamentary Amendments.

Recebido em: 21/11/2016

Revisado em: 10/04/2017

Aprovado em: 11/06/2017 


\section{Introdução}

Para atingir os seus fins, notadamente a garantia da ordem e do bem-estar social, o Estado precisa de recursos financeiros para implementar políticas públicas essenciais ao povo, os quais demandam correta e adequada aplicação, sob pena de se verem frustrados os próprios objetivos estatais. Para tanto, a atividade financeira do Estado desenvolve-se com base no instrumento fundamental do orçamento público, que nada mais é do que um pacto de confiança por meio do qual o povo defere aos seus governantes parcela de seus recursos para que estes sejam utilizados em prol do bem-estar das necessidades prementes sociais. Todavia, não raro, o orçamento público é objeto de constantes disputas de poder e pouca eficiência prática, muito ainda precisando evoluir para atingir seus reais objetivos.

Nesse enfoque, buscar-se-á verificar de que modo o instrumento constitucional do orçamento público deve servir como peça fundamental para fins de concretização dos direitos fundamentais. Inicialmente, serão examinadas as premissas teóricas em que se fundamenta o instituto jurídico do orçamento público dentro do contemporâneo contexto do Estado Constitucional Democrático, situando o debate, em seguida, na tensão entre os poderes e na crise de gestão no âmbito das finanças públicas no Brasil, para, ao final, proceder à análise da recente alteração no ordenamento pátrio advinda a partir da emenda constitucional n. 86/2015, que trouxe a inédita previsão das emendas parlamentares individuais vinculantes.

Considerando a emergente problemática que se apresenta e a premente necessidade de ampliação do seu debate, leva-se a questão em discussão, sobretudo porque se observa pouca difusão na comunidade jurídica de um tema da mais alta relevância. Como elemento estrutural democrático, a peça orçamentária deve refletir, em última instância, o intento de concretização dos direitos e garantias fundamentais, por meio da efetivação das políticas públicas no uso eficiente dos recursos públicos. Nesse sentido, torna-se imperiosa a avaliação responsável no que tange à gestão orçamentária no contexto de seu real objetivo: um instrumento democrático fundamental para a garantia dos direitos fundamentais. 
Para fins de realização da pesquisa científica, a originalidade do presente tema investigativo alinha-se, no que tange aos aspectos metodológicos, ao desenvolvimento da técnica de pesquisa bibliográfica, com destaque para consagradas obras doutrinárias, além de legislações pertinentes e jurisprudência especializada aplicável à espécie, utilizando-se o método de abordagem crítico indutivo e avaliação de dados realizada de maneira qualitativa. Para além da discussão acadêmica, a problemática reveste-se de importância singular, sobretudo, pelos sensíveis impactos que repercutem diretamente na sociedade.

\section{O Orçamento Público no Estado Constitucional Democrático}

O orçamento público encontra suas origens na necessidade de autorizar e controlar a aplicação do dinheiro público, estando relacionado ao desenvolvimento da democracia, como forma de oposição ao antigo Estado arbitrário, em que o soberano considerava-se o detentor do patrimônio originário da coletividade ${ }^{1}$. No seu âmago, portanto, trata-se o orçamento de espécie de delegação para que os representantes do povo possam, em seu nome, realizar o dispêndio dos recursos públicos. Para regular o funcionamento da sociedade e garantir o bem-estar comum, é dever do Estado suprir as necessidades públicas ${ }^{2}$, que se referem ao conjunto das obrigações a que se vinculou junto à sociedade, daí surge a necessidade

\footnotetext{
1 "O princípio de aprovação orçamentária das despesas públicas por decisão legislativa encontra-se largamente reconhecido no constitucionalismo universal. Desconhece-se alguma Constituição que não o contemple. Sua origem confunde-se com o surgimento dos Estados modernos, com a separação dos poderes, com o papel do Legislativo no controle sobre os atos dos governantes, mediante consentimento para a aprovação, por lei, das receitas e despesas, para a consecução dos fins do Estado (defesa, bem comum, etc.). Reminiscências da autorização legislativa para atividade financeira dos governos floresceram na Inglaterra no século XIII. Basta lembrar o compromisso da Magna Charta Libertatum, de 1215, que foi uma das primeiras fintes a evidenciar a submissão de um soberano aos direitos dos que viviam sob seu domínio [...]" (TORRES, 2014, p. 342).

${ }^{2}$ Regis Fernandes de Oliveira define necessidades públicas como "tudo aquilo que incumbe ao Estado prover em decorrência de uma decisão política inserida em norma jurídica (OLIVEIRA, 2015, p. 179). Por sua vez, Luigi Einaudi vê na satisfação destas a missão da economia política. Para leitura, cf. EINAUDI, 1948.
} 
do exercício de uma atividade financeira estatal ${ }^{3}$, o que se faz por meio do orçamento público ${ }^{4}$.

Em termos políticos, a evolução histórica do orçamento público é dignitária de todos os êxitos da luta da sociedade pela democracia e controle dos poderes do Estado em matéria financeira. No Estado Constitucional, que surge a partir do final do século XIX, o orçamento ganha notável importância, não só porque sua formação coincide com a expansão das necessidades financeiras do Estado, mas porque serviria para assegurar o controle legislativo sobre a Administração. E isso porque, para o orçamento, convergem as mais importantes instituições do Estado e da Constituição, na sua permanente relação com a sociedade, quanto ao financiamento do Estado e a atuação na economia. Com o orçamento público, os povos conquistaram o direito de dominar as finanças do Estado e, ao mesmo tempo, o de controlar as escolhas democráticas, ante às preferências reveladas no processo eleitoral, no que concerne à realização contínua dos fins do Estado, da efetividade dos direitos e da apuração do cumprimento dos programas dos governantes eleitos pelo voto popular. (TORRES, 2014, p. 342)

Todavia, durante muito tempo a ideia do orçamento público ficou limitada a uma visão meramente contábil e formalista de receitas versus despesas orçamentárias, progredindo apenas posteriormente para o para-

\footnotetext{
${ }^{3}$ A atividade financeira estatal é regulada no capítulo constitucional sobre finanças públicas na atual CF/88 (artigos 163 a 169), assim como em normas gerais de direito financeiro, com autonomia resguardada consoante artigo 24, I, da CF/88. Para a origem constitucional da previsão legislativa sobre a matéria e os domínios do direito financeiro, cf. Sousa (1954). Ainda, no mesmo sentido, cf. Carvalho Pinto (1949).

${ }^{4}$ Sobre o papel atual do orçamento, expõe Ricardo Lobo Torres: "Neumak indica 4 funções para o orçamento: político-financeira (racionalidade na gestão orçamentária), política (equilíbrio entre grupos políticos), de controle financeiro (do Executivo) e econômica (racionalidade da política econômica). Musgrave aponta 3 objetivos da política orçamentária: "(1) assegurar ajustamentos na alocação de recursos; (2) conseguir ajustamentos na distribuição de renda e (3) garantir a estabilização econômica." (TORRES, 2008, p. 65).
} 
digma de peça fundamental programática de governo ${ }^{5}$. Porém, mais um passo precisa ser dado, agora, para inserir o orçamento público dentro de uma visão constitucional democrática, à luz da concretização dos direitos fundamentais. De fato, o orçamento público relaciona-se intimamente com a garantia dos direitos fundamentais, encontrando-se as finanças públicas, em todas as suas dimensões - tributária, patrimonial, orçamentária, promocional, etc. - em permanente contato com os direitos fundamentais.

Os direitos fundamentais têm uma relação profunda e essencial com as finanças públicas. Dependem, para a sua integridade e defesa, da saúde e do equilíbrio da atividade financeira do Estado, ao mesmo tempo em que lhe fornecem o fundamento da legalidade e da legitimidade. Os direitos fundamentais se relacionam com os diversos aspectos das finanças públicas. Assim é que o tributo, categoria básica da receita do Estado de Direito, é o preço da liberdade, preço que o cidadão paga para ver garantidos os seus direitos e para se distanciar do Leviatã [...]. (TORRES, 2008, p. 499)

Ora, se os cidadãos, com seus recursos vertidos para o sistema, financiam a atividade estatal, é mais do que obrigação do Estado, portanto, que a contrapartida seja ofertada com a concretização de políticas públicas essenciais ao povo, fazendo-se o uso responsável dos recursos públicos por meio da adequada gestão orçamentária. Dessa forma, o dinheiro que sai do povo é aplicado pelos seus representantes e deve voltar por meio dos serviços públicos e investimentos sociais, com fins, em última instância, à tutela dos direitos fundamentais, os quais, vale recordar, gozam de atual hierarquia constitucional e situam-se em status elevado na ordem jurídica, a ponto de vincular o poder público às diretrizes neles contidas.

Registre-se, nesse aspecto, que os direitos fundamentais exibem, além de uma dimensão subjetiva voltada aos seus titulares, também uma

5 "De fato, é o orçamento a personificação do plano ou programa de atuação governamental, expondo a forma de intervenção do poder político no substrato socioeconômico." (ASSONI FILHO, 2009, p. 80). 
dimensão objetiva direcionada ao poder público 6 , contendo "uma ordem dirigida ao Estado no sentido de que a este incumbe a obrigação permanente de concretização e realização dos direitos fundamentais" "Tem-se, dessa forma, uma necessária vinculação do poder público aos direitos fundamentais e, mais que isso, a precisa noção da missão fundamental do orçamento público nessa proteção, do que resulta uma atividade financeira estatal voltada para a consecução desse pleno objetivo. "Em outras palavras: saindo da zona de conforto e de omissão institucional, importa extrair os efeitos da premissa de que o poder existe para os direitos fundamentais, não o contrário" ${ }^{8}$.

Urge, portanto, que o orçamento público passe a ser visto, não apenas no plano formal, mas principalmente material, dentro de uma visão constitucional de instrumento fundamental do Estado (e não de governo). A propósito, segundo pronunciamento da Suprema Corte ${ }^{9}$, trata-se da lei materialmente mais importante do ordenamento jurídico logo abaixo da Constituição, não podendo ser manuseada a pretexto de interesses outros que não sejam a concretização dos direitos fundamentais ${ }^{10}$. De fato, o orçamento público, abaixo da Constituição, é o conteúdo normativo de

6 “[...] como anota José Carlos Vieira de Andrade, "os direitos fundamentais não podem ser pensados apenas do ponto de vista dos indivíduos, enquanto faculdades ou poderes de que estes são titulares", merecendo ser mirados do ponto de vista da comunidade, "como valores ou fins que esta se propõe a prosseguir". A dimensão objetiva representa, assim, uma mais-valia em relação às posições subjetivas, pois dela decorre o reconhecimento dos direitos fundamentais como bases estruturais da ordem jurídica, que espraiam sua influência por todo o direito positivo. Assim, superando a perspectiva exclusivamente individualista, os direitos fundamentais passam a ser vistos como princípios concretizadores de valores a serem protegidos e fomentados pelo Estado." (BINENBOJIM, 2014, p. 75).

${ }^{7}$ Cf. Sarlet (2015, p. 152).

${ }^{8}$ Freitas (2014, p. 77).

${ }^{9}$ ADI n. 4048, STF, voto do Min. Carlos Britto, Rel. Min. Gilmar Mendes, DJ. 14/05/2008. ${ }^{10}$ Invocando Founrouge, destaca Regis Fernandes de Oliveira quanto à importância do orçamento: "Esclarece Giuliani Founrouge que "a evolução das ideias acerca da função do Estado na atividade econômica, singularmente acelerada no correr do século, determinou modificações substanciais no conceito de orçamento. Assim como aquele mudou sua qualidade de espectador transformando-se em autor do processo vital da nação, assim também o orçamento deixou de ser um mero documento de caráter administrativo e contábil, para assumir significação de elemento ativo com gravitação primordial sobre 
maior importância para a continuidade do Estado ${ }^{11}$. É nesse contexto de necessária vinculação dos poderes públicos à concretização dos direitos fundamentais que se insere, então, o orçamento público no atual Estado Constitucional de Democrático, como um elemento propulsor da consolidação da democracia ${ }^{12}$.

Lembre-se que, se a constitucionalização do direito ${ }^{13}$ é fenômeno que atinge todos os seus ramos, diferentemente também não seria no âmbito das finanças públicas e da atividade financeira do Estado. Da mesma forma que qualquer outra lei deve estar em consonância com os mandamentos constitucionais, assim também ocorre necessariamente com as leis orçamentárias ${ }^{14}$, razão pela qual se faz necessária uma abertura para a noção do orçamento público como ferramenta constitucional fundamental do Estado na concretização dos direitos fundamentais e na garantia do princípio democrático, visão esta que, não raro, permanece pouco difundida na comunidade jurídica e ainda não posta plenamente em prática.

[...] o que se pretende demonstrar é a urgente necessidade de constitucionalização do sistema orçamentário brasileiro. Embora as linhas gerais do processo orçamentário sejam disciplinadas na própria Constituição, sustenta-se aqui que os dispositivos constitucionais em questão têm sido interpretados de forma isolada, sem que seja levada em conta - ao menos na extensão adequada - a influência de normas constitucionais fundamentais, como os princípios da sepa-

as atividades gerais da comunidade" (OLIVEIRA, 2015, p. 601). Para recuperação da leitura, cf. Founrouge (2001, p. 125).

${ }^{11}$ Corroborando o entendimento da Suprema Corte, cf. Torres (2014, p. 340).

${ }^{12}$ Valiosa a doutrina de Luigi Ferrajoli ao abordar a garantia à democracia material, inserindo a chamada 'esfera do não decidível': "[...] aquilo que nenhuma maioria pode validamente decidir, isto é, a violação ou a restrição dos direitos de liberdade, e aquilo que nenhuma maioria pode legitimamente deixar de decidir, isto é, a satisfação dos direitos sociais constitucionalmente estabelecidos." (FERRAJOLI, 2015, p. 11).

${ }^{13}$ Para um estudo abrangente do tema, cf. Barroso (2006).

${ }^{14}$ A Constituição Federal de 1988, adota a tripartição do planejamento orçamentário, nos termos do seu artigo 165, com o orçamento englobando três espécies de leis orçamentárias, qual sejam, o plano plurianual (PPA), a lei de diretrizes orçamentárias (LDO) e a lei orçamentária anual (LOA), acaba por reforçar a constatação de que o planejamento é exigência ao moderno conceito de orçamento, decorrente do princípio da programação. 
ração dos poderes e democrático. É necessário, portanto, inserir a Constituição orçamentária no contexto mais amplo da Constituição em seu conjunto. (MENDONÇA, 2010, p. 126-127)

Isso significa que as escolhas em matéria de gastos públicos não constituem um tema integralmente reservado à deliberação política, mas recebem importante incidência de normas jurídicas constitucionais ${ }^{15}$. Amolda-se, assim, o orçamento público como base fundamental ao Estado Constitucional Democrático. Dessa forma, direitos fundamentais e democracia são pilares fundamentais sobre os quais se deve pautar toda a atividade financeira do Estado ${ }^{16}$, encontrando-se este em necessária subsunção e estrita vinculação a tais mandamentos, os quais, amparados sob o manto constitucional, exercem influência decisiva na definição dos contornos da atividade estatal e, portanto, na gestão financeira do Estado ${ }^{17}$.

15 "Se a Constituição contém normas nas quais estabeleceu fins públicos prioritários, e se tais disposições são normas jurídicas, dotadas de superioridade hierárquica e de centralidade no sistema, não haveria sentido em concluir que a atividade de definição das políticas públicas - que irá, ou não, realizar esses fins - deve estar totalmente infensa ao controle jurídico. Em suma: não se trata da absorção do político pelo jurídico, mas apenas da limitação do primeiro pelo segundo.” (BARCELLOS, 2005, p. 92).

${ }^{16}$ Nesse ponto, importa destacar a lúcida observação de Daniel Sarmento: "Embora na visão contemporânea de Estado Democrático de Direito, democracia e constitucionalismo sejam vistos como valores complementares, interdependentes e até sinérgicos, a correta dosagem dos ingredientes desta fórmula é essencial para o seu sucesso. Por um lado, o constitucionalismo e limitações ao poder em demasia podem sufocar a vontade popular e frustrar a autonomia política do cidadão, como co-autor do seu destino coletivo. Por outro lado, uma 'democracia' sem limites tenderia a pôs em sério risco os direitos fundamentais das minorias, bem como outros valores essenciais, que são condições para a manutenção ao longo do tempo da própria empreitada democrática." (SARMENTO, 2006, p. 97).

17 “[...] o sistema de direitos fundamentais e o princípio democrático, tal como delineados na Constituição, exercem também influência decisiva na definição dos contornos da atividade administrativa. À centralidade desses pilares constitutivos e legitimadores da ordem constitucional deve corresponder uma igual centralidade na organização e funcionamento da Administração Pública.” (BINENBOJIM, 2014, p. 71). 


\section{Debates Quanto à Natureza Jurídica do Orçamento}

Uma vez inserido o orçamento público na compreensão de fundamental instrumento do Estado Constitucional Democrático, cumpre analisar sua natureza jurídica, da qual decorrem importantes reflexos. Em princípio, sempre originou controvérsia no debate jurídico acadêmico o tema referente ao exame da natureza jurídica do orçamento e suas implicações práticas. Correntes doutrinárias protagonizam o acalorado debate com teses que buscam identificar a essência jurídica do instituto, como se verá adiante. A propósito, o ordenamento jurídico brasileiro trata de prever o orçamento público como Lei, a teor do artigo 165 da CF/88: "Leis de iniciativa do Poder Executivo estabelecerão: I - o plano plurianual; II - as diretrizes orçamentárias; III - os orçamentos anuais". A discussão pauta-se em determinar se é o orçamento uma lei do ponto de vista material ou se tem caráter meramente formal.

Problema que há mais de um século preocupa a ciência jurídica é o da natureza do orçamento. Cumpre determinar se é uma lei material, com conteúdo de regra de direito e eficácia inovadora, ou se é mero ato administrativo, que só do ponto de vista formal reveste as características da lei. Antes, porém, torna-se necessário averiguar se a questão da natureza do orçamento tem importância prática. Alguns autores entendem-na como um problema aparente ou falso. [...] Parece-nos que, apesar dos desencontros, o problema da natureza do orçamento continua relevante, eis que dele dependem outras questões: a da obrigatoriedade de o Executivo realizar as despesas previstas; a da criação de direitos subjetivos para terceiros; a da revogação das leis financeiras materiais. (TORRES, 2008, p. 94-95)

Por trás de uma feição aparentemente formal, o tema reveste-se de importância extrema. Ao estudar a essência da norma orçamentária poder-se-á verificar se o orçamento é instrumento que vincula a Administração, criando expectativas de efetiva realização e estabelecendo limites de flexibilização orçamentária, ou se apenas é instrumento que autoriza a aplicação dos recursos públicos. Sendo o orçamento lei não somente do ponto de vista formal, mas revestindo-se dessa natureza também no plano material, 
tornar-se-ia instrumento impositivo a vincular o Executivo à sua fiel observância. Ao contrário, possuindo natureza somente de lei formal, mas com conteúdo substancialmente administrativo, o orçamento teria apenas caráter autorizativo, sem que haja o dever legal de sua efetiva implementação.

No que concerne à controvérsia jurídica acerca da natureza do orçamento, é possível identificar, basicamente, três teses distintas ${ }^{18}$ : (a) Teoria da Lei Material: o orçamento é lei não apenas formal, mas também material, na medida em que se origina de um órgão legiferante, não havendo porque indagar sobre a sua substância; (b) Teoria da Lei Formal: o orçamento, embora com aparência de lei, não é lei em sentido material, mas tão somente lei formal; (c) Teoria da Lei "Sui Generis": engloba as demais concepções a partir das quais o orçamento não é visto como lei material nem formal, tratando-se de uma lei especial.

A primeira corrente, referente à Teoria da Lei Material, defendeu-a inicialmente, dentre outros, Myrbach-Rheinfeld e Honnel, adotando-a também parte da doutrina italiana, entre os quais, Ingrosso e Micheli. Mas é na Espanha contemporânea que se fortaleceu essa corrente doutrinária, sobretudo a partir de Sainz de Bujanda e Rodrigues Bereijo ${ }^{19}$. Nessa acepção, o orçamento público, considerado lei formal e material, em nada se difere dos demais atos emanados pelo legislativo no que tange ao seu comando normativo. No Brasil, a tese não foi absorvida por muitos seguidores de prestígio.

\footnotetext{
${ }_{18}$ Acerca das teorias que buscam explicar a natureza jurídica do orçamento, cf. Torres (2008, p. 93-94).

${ }^{19}$ Quanto aos dois principais expoentes da teoria da lei material na Espanha, discorre a respeito Ricardo Lobo Torres: "Sainz de Bujanda considera o orçamento como "uma lei em sentido pleno, de conteúdo normativo", com "eficácia material constitutiva ou inovadora" e com todas as características de valor e força da lei, como sejam "a impossibilidade de que suas normas sejam derrogadas ou modificadas por simples regulamentos e a possibilidade de modificar e até derrogar normas precedentes de hierarquia igual ou inferior"; Rodrigues Bereijo afirma que o Direito Orçamentário deveria se chamar Direito do Gasto Público, pois o orçamento, lei material e formal, converte-se em verdadeira regulação jurídica do gasto público e em mera ordenação contábil dos tributos.” (TORRES, 2008, p. 98). Para maior aprofundamento no tema, cf. Bujanda (1955).
} 
Por sua vez, a segunda corrente, referente à Teoria da Lei Formal, foi desenvolvida inicialmente a partir de Paul Laband, como resistência à concepção anterior, entendendo que o aspecto formal não poderia, por si só, fazer do orçamento uma lei, entendida esta em seu sentido material. Destarte, afirma que a utilização da forma legal em nada altera o conteúdo do orçamento, entendendo que o orçamento apresenta extrinsecamente a forma de uma lei, mas seu conteúdo não contém regra jurídica, tratando-se de um plano de gestão. Aderiram à tese da lei formal, entre outros, juristas italianos como Graziani, Santi Romano, Berliri e Balladore-Pallieri, influenciando também autores franceses, sobressaindo-se Gaston Jèze ${ }^{20}$.

Por último, a Teoria da Lei "Sui Generis", na qual podem ser incluídos aqueles que não consideram ser o orçamento lei material ou formal, tratando-se de uma espécie de instituto singular, concepção liderada por Léon Duguit, o qual identifica o orçamento, em relação às despesas, com natureza administrativa ou de ato-condição, sendo em relação à receita tributária lei em sentido material, notadamente quando autoriza a cobrança de tributos. Obviamente, Duguit analisou ordenamentos jurídicos em que a autorização para a cobrança de tributos obedece ao princípio da anualidade tributária, exigindo-se prévia inclusão de autorização no orçamento como condição à cobrança de tributo.

Embora não haja unanimidade, a doutrina majoritária nacional aponta para identificar o orçamento como lei formal ${ }^{21}$. Na mesma linha,

20 "As ideias iniciais de Laband influenciaram os autores franceses, sendo de notar que entre eles sobressaiu a figura de Gaston Jèze, que defendia o ponto de vista de que o orçamento jamais é uma lei: quanto à receita pública, é, nos países que adotam a regra da anualidade tributária, um ato-condição, pois "preenche a condição exigida pelo direito positivo para o exercício da competência dos agentes administrativos”, e, nos países que abandonaram a regra na anualidade dos impostos, não tem significação jurídica; quanto à despesa pública, ou é um ato-condição - que preenche a condição necessária para o agente administrativo realizar o gasto - ou não tem significação jurídica, como acontece com as despesas relativas a serviços públicos não criados por lei.” (TORRES, 2008, p. 95).

${ }^{21}$ É possível citar, nesse sentido, a lição de Ricardo Lobo Torres: "A teoria de que o orçamento é lei formal, que apenas prevê as receitas públicas e autoriza os gastos, sem criar direito subjetivos e sem modificar as leis tributárias e financeiras, é, a nosso ver, a que melhor se adapta ao direito constitucional brasileiro. Tem sido defendida, entre nós, 
já consagrou entendimento a Corte Suprema pacificando o tema ao definir tratar-se o orçamento de lei formal de efeitos concretos ${ }^{22}$. Todavia, em que pese a linha perfilhada no sentido de que o orçamento possui natureza de lei formal, apenas prevendo as receitas e autorizando os gastos, sem criar, em princípio, direitos subjetivos, importa verificar que a própria Suprema Corte, alterando entendimento anterior ${ }^{23}$, já passou a admitir a plena possibilidade de submissão das normas orçamentárias ao controle de constitucionalidade ${ }^{24}$. Nesse ponto, considerando a relevância do tema, vale transcrever trecho do voto do Min. Ayres Britto proferido na ADI 4.049-MC:

[...] Em se tratando de lei orçamentária, avulta um traço peculiar: abaixo da Constituição não há lei mais importante para a Admi-

principalmente sob a influência da obra de Jèze, por inúmeros autores de prestígio, ao longo de muitos anos e sob várias escrituras constitucionais". (TORRES, 2008, p. 96).

${ }^{22}$ Entendendo tratar-se de lei formal, é possível citar o julgado STF: "EMENTA: DIREITO CONSTITUCIONAL E TRIBUTÁRIO. CONTRIBUIÇÃO PROVISÓRIA SOBRE MOVIMENTAÇÃO FINANCEIRA - C.P.M.F. AÇÃO DIRETA DE INCONSTITUCIONALIDADE "DA UTILIZAÇÃO DE RECURSOS DA C.P.M.F." COMO PREVISTA NA LEI N ${ }^{\circ}$ 9.438/97. LEI ORÇAMENTÁRIA: ATO POLÍTICOADMINISTRATIVO - E NÃO NORMATIVO. IMPOSSIBILIDADE JURÍDICA DO PEDIDO: ART. 102, I, "A", DA C.F. 1. Não há, na presente Ação Direta de Inconstitucionalidade, a impugnação de um ato normativo. Não se pretende a suspensão cautelar nem a declaração final de inconstitucionalidade de uma norma, e sim de uma destinação de recursos, prevista em lei formal, mas de natureza e efeitos políticoadministrativos concretos [...]”. (ADI 1640/DF, Relator(a): Min. SYDNEY SANCHES, Julgamento: 12/02/1998).

23 “[...] sob o fundamento de que as leis orçamentárias revelam-se como atos normativos de efeitos meramente concretos, sendo apenas lei apenas em sentido formal, entendiase serem incabíveis as ações de controle concentrado que impugnavam este tipo de lei. Entendia-se, nesse primeiro momento, que a impugnação de lei orçamentária não representaria, a rigor, o ataque a um ato normativo, mas a um ato político-administrativo concreto de destinação de recursos, que apenas formalmente se reveste como lei. Seria descabido o controle de constitucionalidade, portanto, por não se tratar de ato normativo. Foi o que restou assentado, verbia gratia, no julgamento da ADI 1.640, Rel. Min. Sydney Sanches, DJ de 03.04.1998." (FUX, 2016, p. 27-28).

${ }^{24}$ Nesse sentido, é possível citar, dentre outros precedentes, os paradigmáticos julgados da Suprema Corte: ADI 4.048-MC, Rel. Min. Gilmar Mendes, DJe 21.08.2008 e ADI 4.049-MC, Rel. Min. Ayres Britto, DJe 08.05.2009. 
nistração Pública, porque o orçamento anual é o diploma legal que mais influencia no destino de toda a coletividade administrada, na medida em que fixa todas as despesas e prevê todas as receitas públicas para um determinado exercício financeiro. Donde se chamar a lei orçamentária de lei de meios. Deixá-la de fora do controle de constitucionalidade em processos objetivos parece um dar às costas ao reconhecimento de uma relevância que é tão intrínseca quanto superlativa. Lei orçamentária que, formalmente, é de natureza ordinária, não se nega. Materialmente, porém, é a lei que mais se aproxima da Constituição na decisiva influência que projeta sobre toda a máquina estatal administrativa e, por isso mesmo, na qualidade de vida de toda a sociedade civil. (ADI 4.049-MC, Rel. Min. Ayres Brito, DJe 08.05.2009)

Ademais, a jurisprudência da Corte Maior já é pacífica quanto à possibilidade de judicialização de políticas públicas, ainda que não previstas no orçamento, reconhecendo a dimensão política da jurisdição constitucional e a inoponibilidade do arbítrio estatal frente aos direitos fundamentais ${ }^{25}$. O Estado não pode demitir-se do encargo de tornar efetivos os direitos fundamentais, sob pena de comprometer a integridade da ordem constitucional. Nem mesmo poderá invocar arbitrariamente a cláusula da reserva do possível para fins de se eximir, injustificadamente, da missão que lhe compete na tutela dos direitos fundamentais ${ }^{26}$.

25 "Ementa: arguição de descumprimento de preceito fundamental. A questão da legitimidade constitucional do controle e da intervenção do poder judiciário em tema de implementação de políticas públicas, quando configurada hipótese de abusividade governamental. Dimensão política da jurisdição constitucional atribuída ao supremo tribunal federal. Inoponibilidade do arbítrio estatal à efetivação dos direitos sociais, econômicos e culturais. Caráter relativo da liberdade de conformação do legislador. Considerações em torno da cláusula da 'reserva do possível'. Necessidade de preservação, em favor dos indivíduos, da integridade e da intangibilidade do núcleo consubstanciador do 'mínimo existencial'. Viabilidade instrumental da arguição de descumprimento no processo de concretização das liberdades positivas." (ADPF 45/DF, DJ 04/05/2004).

26 "A limitação de recursos existe e é uma contingência que não se pode ignorar. O intérprete deverá levá-la em conta ao afirmar que algum bem pode ser exigido judicialmente, assim como o magistrado, ao determinar seu fornecimento pelo Estado. Por outro lado, não se pode esquecer que a finalidade do Estado ao obter recursos, para, em seguida, gastá-los sob a forma de obras, prestação de serviços, ou qualquer outra 
Diante do presente cenário, embora seja majoritário o entendimento do orçamento enquanto lei formal - sem, portanto, em tese, gerar direitos subjetivos à sua realização - caminha-se, atualmente, para uma atual possibilidade de judicialização de relações políticas e sociais, bem como a impugnação da lei orçamentária via controle de constitucionalidade, o que significa que não se concebe mais a sua utilização para fins outros que não sejam o dever de cumprimento do Estado frente às necessidades públicas. Todavia, na prática, o orçamento ainda continua a ser utilizado como instrumento de governo, daí porque surge o anseio social em conferir-lhe maior impositividade, discussão que vem ganhando espaço atualmente.

\section{A Crise no Âmbito da Gestão das Finanças Públicas no Brasil}

Considerando a necessidade de inserção do orçamento público como instrumento de Estado para a concretização dos direitos fundamentais e consolidação da democracia, tem-se revelado tendência crescente, hodiernamente, o debate acerca da vinculação do poder público à peça orçamentária. Sendo a gênese do orçamento uma autorização do povo para a utilização dos recursos públicos, não é errado concluir que, ao não se efetivar sua aplicação conforme consentida, estar-se-á agindo à revelia daquilo que foi autorizado e, portanto, em arrepio ao próprio regime democrático, que exige a subsunção dos governantes aos objetivos e fundamentos constitucionais. De fato, o caráter autorizativo do orçamento não pode ser invocado para originar uma benesse de forma a ser possível descumpri-1o ${ }^{27}$.

política pública, é exatamente realizar os objetivos fundamentais da Constituição. A meta central das Constituições modernas, e da Carta de 1988 em particular, pode ser resumida, como já exposto, na promoção do bem-estar do homem, cujo ponto de partida está em assegurar as condições de sua própria dignidade, que inclui, além da proteção dos direitos individuais, condições materiais mínimas de existência." (BARCELLOS, 2002, p. 245). 27 “Já não se pode admitir um orçamento sem compromissos, apenas para cumprir determinação legal. Já não se aceita o governante irresponsável. Já longe vai o tempo em que se cuidava de mera peça financeira, descompromissada com os interesses públicos. Já é passado o momento político em que as previsões frustravam a esperança da sociedade. A introdução do orçamento participativo foi o primeiro passo. Para que serve? Está 
Todavia, apesar da dissidência doutrinária ${ }^{28}$, o entendimento predominante ainda é o de que permanece a essência que deu origem à peça orçamentária, continuando o orçamento a ser visto com natureza autorizativa, o que significa que o fato de determinada verba estar nele prevista não obriga o governante a realizá-la, apenas o autoriza, não gerando direitos subjetivos a terceiros eventual previsão de despesa em lei orçamentária. Este, aliás, sempre foi o entendimento do Supremo Tribunal Federal ${ }^{29}$, mesmo em época anterior à Constituição de 1988, não alterado até os dias atuais, posicionando-se no sentido de conferir ao orçamento caráter autorizativo, muito embora se reconheça, hoje, a possibilidade de judicialização de políticas públicas e o exercício do controle de constitucionalidade da peça orçamentária.

o governantes obrigado a acolher as propostas que lhe forem apresentadas? Para que ouvir a sociedade? Trata-se de mero jogo lúdico? É mera diversão, tal como os jogos com os cristãos da Antiga Roma, que eram devorados pelos leões para gáudio de uma platéia destituída de sentido ético? Serviria de mera burilação de ocupante desocupado do governo? Mera elucubração mental para brincadeira com os interesses públicos? A evidência das respostas às questões formuladas leva-nos à conclusão de que o orçamento não pode ser mera peça financeira, nem apenas simples plano de governo, mas representa o compromisso político de cumprimento de promessas sérias levadas ao povo. A previsão desperta esperança, expectativa de satisfação dos compromissos, certeza de que os desejos serão atendidos." (OLIVEIRA, 2011).

${ }^{28}$ Levantando a tese da impositividade do orçamento, é possível citar, o entendimento de Eduardo Mendonça: "Não se nega a evidência de que o orçamento no Brasil, em termos práticos, tem funcionado como mera autorização para que os gastos sejam realizados. Destaca-se apenas a peculiaridade de tal situação não decorrer de forma expressa de nenhum dispositivo normativo vigente, embora seja no mínimo inusitado presumir que uma lei não vincula a Administração ou o faz apenas parcialmente, na forma de limite. A legislação que trata especificamente da matéria é dúbia, começando pela Constituição, podendo indicar tanto um modelo autorizativo, como um modelo impositivo. Apesar disso, sustenta-se no presente trabalho que a melhor leitura do texto constitucional aponta no sentido de que a execução orçamentária deve ser, em princípio, vinculada." (MENDONÇA, 2010, p. 100-101).

29 "EMENTA: ORCAMENTO. VERBAS DESTINADAS A INSTITUIÇÃO ASSISTENCIAL. - A PREVISÃO DE DESPESA, EM LEI ORCAMENTARIA, NÃO GERA DIREITO SUBJETIVO A SER ASSEGURADO POR VIA JUDICIAL. - AÇÃO RESCISÓRIA IMPROCEDENTE. (STF, AR 929 / PR, Relator(a): Min. RODRIGUES ALCKMIN, Julgamento: 25/02/1976). 
Contudo, não bastasse toda a polêmica quanto ao caráter autorizativo ou impositivo do orçamento, vale observar o desvirtuamento histórico da peça orçamentária. Ả margem de cumprir rigorosamente o orçamento, é comum ao Executivo promover inúmeras alterações na sua execução, as quais se efetuam, por exemplo, mediante remanejamento de dotações e cancelamentos de despesas ou, de modo menos evidente, pela mera inexecução das dotações. Várias manobras acabam por frustrar a expectativa inicial estabelecida na lei orçamentária, instaurando-se uma efetiva crise no âmbito das finanças públicas no Brasil, percebendo-se uma constante tensão entre os poderes na esfera da gestão orçamentária.

Nesse contexto, fica demonstrado que além das competências inerentes ao exercício de suas atribuições intrínsecas, o sistema jurídico confere uma série de instrumentos de flexibilidade que permitem ao Executivo, durante a fase de execução orçamentária, deixar de dar cumprimento efetivo ao orçamento público da forma como aprovado pelo Poder Legislativo, aumentando o poder do Chefe do Executivo na condução das finanças públicas do Estado. Entre os mecanismos, destacam-se a abertura de créditos adicionais, a previsão de reserva de contingência para o atendimento de despesas não previstas no orçamento e o contingenciamento de despesas, que permite ao Executivo afastar-se das disposições orçamentárias em razão da não-realização das receitas previstas. A par dos instrumentos de flexibilidade, existem outros mecanismos de que se vale o Chefe do Poder Executivo para alcançar um maior domínio no quadro da gestão financeira, mecanismos estes que, embora abarcados pelo sistema jurídico, são, no mais das vezes, utilizados de forma desvirtuada em relação às suas reais finalidades, os quais foram aqui denominados mecanismos auxiliares de governabilidade. Nesse quadrante, toma relevo o uso das medidas provisórias e o exercício da prerrogativa de estimar receitas por ocasião da elaboração da peça orçamentária, além dos demais mecanismos inerentes ao presidencialismo de coalizão, por meio do qual o Poder Executivo busca o apoio parlamentar às suas iniciativas em troca da liberação de recursos orçamentários e da nomeação para o preenchimento de cargos em comissão na estrutura governamental. (DALLAVERDE, 2013, p. 10-11) 
Na prática, depara-se rotineiramente com mecanismos de flexibilização ${ }^{30}$ adotados pelo Executivo que desvirtuam o real objetivo do orçamento. As expectativas criadas não demoram muito para serem frustradas, convertendo-se o orçamento em mera peça retórica. A decisão de gastar é eminentemente política, porém, também jurídica na medida em que deve necessário respeito aos ditames constitucionais. O processo de elaboração das leis orçamentárias acaba por esvaziar seu sentido quando a discricionariedade é utilizada como manobra para justificar a inexecução daquilo que foi exaustivamente discutido e planejado ${ }^{31}$.

Por outro lado, não bastasse a crise já existente entre Executivo e Legislativo, também o Judiciário é chamado a intervir no âmbito das finanças públicas ${ }^{32}$, não se podendo deixar de mencionar a crescente interferência da instância judiciária na distribuição de recursos orçamentários

30 "Na prática, os mecanismos de flexibilidade orçamentária acabam conferindo ampla margem de discricionariedade ao Poder Executivo, na medida em que permitem que as dotações orçamentárias aprovadas pelo Legislativo sejam alteradas. Assim, muito embora a previsão de tais mecanismos se faça necessária, até mesmo para o atendimento de situações imprevisíveis e urgentes, acabam, por vezes, transformando-se em um instrumento de concentração de poder [...]." (DALLAVERDE, 2013, p. 119).

31 "O sistema atual permite que as decisões políticas produzidas no processo deliberativo sejam inteiramente esvaziadas e substituídas por decisões unilaterais e imotivadas do Poder Executivo. Nesse contexto, políticas públicas relevantes - decididas pelo procedimento majoritário em sua essência - têm sido desconsideradas de forma pouco consistente, para dizer o mínimo. É certo que o controle desse quadro passa também, e talvez sobretudo, pela cidadania fiscal, mas não se deve tomar como fato da vida um sistema orçamentário que institucionaliza o referido esvaziamento." (MENDONÇA, 2010, p. 90-91)

${ }^{32}$ O Supremo Tribunal Federal vem reconhecendo a possibilidade de interferência do Poder Judiciário na alocação de recursos em matéria orçamentária. Ilustra-se julgado da Corte Maior nesse sentido, a par da vasta jurisprudência acerca da matéria: "Embora resida, primariamente, nos Poderes Legislativo e Executivo, a prerrogativa de formular e executar políticas públicas, revela-se possível, no entanto, ao Poder Judiciário, determinar, ainda que em bases excepcionais, especialmente nas hipóteses de políticas públicas definidas pela própria Constituição, sejam estas implementadas pelos órgãos estatais inadimplentes, cuja omissão - por importar em descumprimento dos encargos político-jurídicos que sobre eles incidam em caráter mandatório - mostra-se apta a comprometer a eficácia e a integridade de direitos sociais e culturais impregnados de estatura constitucional" (REAgR 410715/SP, Rel. Min. Celso de Mello, DJ de 03.02.2006). 
por meio do exercício da atividade jurisdicional ${ }^{33}$. De fato, como poder contra majoritário e pressuposto da democracia material entra em cena o ativismo judicial, inclusive em matéria orçamentária. Está-se, enfim, diante de uma verdadeira tensão entre os três poderes, sendo atualmente reconhecida a legitimidade constitucional do controle e da intervenção do Poder Judiciário em tema de implementação de políticas públicas.

Nesse contexto, além da participação dos Poderes Legislativo e Executivo em matéria orçamentária, não se poderia mencionar a crescente interferência do Poder Judiciário na distribuição de recursos orçamentários, por meio do desenvolvimento da atividade jurisdicional. Dentro desse contexto, ressalta a controvérsia relativa às decisões judiciais cujo teor acaba por interferir na alocação de recursos orçamentários, havendo de se compatibilizar os direitos e garantias constitucionais com a competência constitucional para a formulação e a execução de políticas públicas, atribuídas aos Poderes Executivo e Legislativo. (DALLAVERDE, 2013, p. 108)

Nessa esteira, surge o anseio social pela mudança de paradigma com a passagem para o orçamento impositivo ${ }^{34}$. Atualmente, a regra é de

33 "Nesse passo, reconhece-se a dificuldade em delimitar o campo de atuação do Poder Judiciário, na medida em que é bastante subjetiva a realização da compatibilização de valores albergados pela Constituição com a opção pelo gasto público, tarefa esta que compete primordialmente ao Poder Executivo e ao Poder Legislativo, por meio de sua participação na elaboração e aprovação das propostas orçamentárias. A Constituição aponta vetores para a realização de gastos públicos, como ocorre no tocante à educação, às ações e serviços de saúde, e ao atendimento aos fundos, que podem servir como parâmetro de aferição do cabimento ou não da interferência do Poder Judiciário.” (DALLAVERDE, 2013, p. 110-111).

${ }^{34}$ Defendendo a mudança na percepção do orçamento meramente autorizativo, destaca-se a lição de Eduardo Mendonça: "Como visto, a lei orçamentária anual responde pela importante função de equacionar receitas e despesas públicas, tendo em vista a satisfação das necessidades coletivas. Em um contexto de recursos limitados, a realização de uma opção de investimento significa que outros serão preteridos. Nesse sentido, modificar ou ignorar uma dotação orçamentária significa deixar de realizar concretamente um investimento que fora considerado não apenas relevante, mas também mais relevante do que muitos outros. Isso não deve ser tratado como um acontecimento banal. Ao contrário, deve ser encarado com cautela, ainda que, ao final, o corte venha a ser considerado necessário para viabilizar outras atividades. O orçamento é aprovado pelo Poder 
que o orçamento é autorizativo, salvo quando há vinculação expressa ${ }^{35}$. Talvez seja a hora de se inverter a lógica, estabelecendo que as verbas autorizadas na lei orçamentária, na sua maioria, deveriam vincular o administrador, salvo se houver a demonstração justificada da inviabilidade quanto à sua execução. Na verdade, o desejo de um orçamento cada vez mais vinculado, dotado de impositividade ao gestor, reflete, no seu íntimo, o anseio da população pela efetivação das políticas públicas, transferindo-se para a lei a confiança que não se tem nos governantes, revelando crescente tendência de descrença das instituições e, especialmente, do Poder Executivo.

Nessa linha, vale registrar relevante precedente no âmbito da $\mathrm{Su}-$ prema Corte no sentido de conferir maior imperatividade ao orçamento público, consoante decisão monocrática liminar proferida pelo Min. Luiz Fux na ADI 4.663, em que se reconheceu que "as normas orçamentárias ostentam, segundo a lição da moderna doutrina financista, a denominada força vinculante mínima ${ }^{36}$, a ensejar a imposição de um dever prima fa-

Legislativo, por mei formal, não havendo motivo para presumir que as opções de gasto assim definidas sejam uma mera recomendação ao Poder Executivo. Aliás, vale lembrar que as leis são presumidamente imperativas, assim como os demais atos praticados pelos agentes do Poder Público nas respectivas esferas de competência." (MENDONÇA, 2010, p. 100).

${ }^{35}$ Por haver vinculação em parte do orçamento, notadamente quanto às despesas constitucionais obrigatórias, há quem defenda ter o orçamento não um caráter autorizativo, mas híbrido, como expõe a doutrina de Marcus Abraham: "Atualmente, podemos afirmar que o orçamento público no Brasil possui um perfil dúplice: em parte é impositivo, e em parte é autorizativo. É impositivo na parte cuja execução faz-se obrigatória (despesas constitucionais e legais), e autorizativo na parcela remanescente, passível de contingenciamento e de não execução. Assim, a nosso ver, restam superados os entendimentos que generalizavam e afirmavam ser meramente autorizativo o orçamento público no Brasil.” (ABRAHAM, 2016, p. 307).

${ }^{36}$ Nesse ponto, embora se reconheça no precedente da ADI 4.663 no âmbito da Suprema Corte efetivo avanço no sentido da gradativa evolução para o paradigma da imperatividade do orçamento público, deixe-se claro que a chamada força vinculante mínima não se confunde com orçamento impositivo, como bem explica Eduardo Mendonça: “[...] Vinculação mínima: cuida-se aqui do mínimo do mínimo, apenas o dever de motivar o descumprimento da previsão inicial. A rigor, sequer se trata de verdadeira vinculação, salvo por exigir que o administrador leve em conta a decisão orçamentária e forneça motivos para a sua superação. Com isso, evita-se, ao menos, que o contingenciamento 
cie de acatamento, ressalvada a motivação administrativa que justifique o descumprimento com amparo no postulado da razoabilidade" 37 . Decorrência dessa evolução jurisprudencial, há quem já fale, inclusive, no orçamento como lei em sentido material ${ }^{38}$. Todavia, pensa-se ser cedo para tanto, melhor seria entender como lei formal de efeitos concretos, possuidora de uma vinculação mínima em seu conteúdo, nos termos do entendimento da Suprema Corte.

De toda sorte, o que importa é que, fruto das manobras desvirtuadas do Executivo na gestão das finanças públicas, da qual resulta nítida tensão entre os poderes em matéria orçamentária e insatisfação pela ineficiência estatal no atendimento das necessidades sociais, evolui-se a passos largos no sentido de conferir maior impositividade à peça orçamentária. Nessa perspectiva, a propósito, importa consignar recente alteração vinda por meio da emenda constitucional n. 86/2015, intitulada 'PEC do orçamento impositivo', reformando a Carta Magna para tornar obrigatória a execução da programação orçamentária na parcela vinculada às emendas individuais parlamentares, como se passará a detalhar adiante.

passe despercebido, obrigando o administrador a assumir formalmente uma posição e sustentá-la no espaço público. Como se sabe, a exigência de motivação encontra amparo em diversos dispositivos constitucionais e legais.” (MENDONÇA, 2010 p. 395-396)

37 "Novas vozes, inspiradas nos princípios da separação dos poderes (CF, art. $2^{\circ}$ ), da legalidade orçamentária (CF, art. 165, caput e incs. I a III) e da democracia (CF, art. $1^{\circ}$, caput), têm apontado para a necessidade de se conferir força vinculante ao orçamento público, como forma de reduzir o incontrastável arbítrio do Poder Executivo em prol da imposição de um dever relativo - e não verdadeiramente absoluto, saliente-se - de observância das normas do orçamento anual. No limite das possibilidades das práticas constitucionais ainda vigentes no cenário nacional, impõe-se reconhecer ao menos a denominada vinculação mínima das normas orçamentárias, capaz de impor um dever prima facie de acatamento, ressalvada a motivação administrativa que justifique o descumprimento com amparo na razoabilidade." (FUX, 2016, p. 45)

${ }^{38}$ Nesse sentido é o pensamento de Marcus Abraham, ao defender a ideia de que, para doutrina e jurisprudência atual majoritárias, o orçamento já seria considerado "lei em sentido material, de conteúdo concreto, já que contempla um plano de governo a ser cumprido, principalmente quanto aos gastos e aplicações de recursos, destacando-se, inclusive, que os atos que dela são controlados por normas de responsabilidade em caso de descumprimento", não se tratando de algo simplesmente formal. A respeito, cf. Abraham (2016, p. 315). 


\section{Orçamento Impositivo e Emendas Parlamentares Vinculantes}

A chamada PEC do orçamento impositivo, convertida na emenda constitucional n. 86/2015, de 17 de março de 2015, foi originalmente incluída em pauta no Legislativo por meio da PEC 22A/2000, transformada em PEC 356/2006 e, posteriormente, em PEC 358/2013. Nasceu com redação original prevendo a vinculação de toda a programação contida na Lei Orçamentária Anual (LOA). Após quinze anos de tramitação, foi aprovada tornando impositiva apenas as emendas individuais parlamentares. Deixou, portanto, de ser a PEC do orçamento impositivo para se tornar a PEC das emendas parlamentares impositivas.

Entretanto, se o processo orçamentário irá ser alterado, a conjuntura política no qual ele está inserido também sofrerá necessárias repercussões. Porém, o debate sobre as reformas orçamentárias feitas no Brasil tem negligenciado aspectos inerentes à própria dinâmica de decisão das reformas, como as configurações de poder. De fato, a proposta de adoção do orçamento impositivo no Brasil ${ }^{39}$, da forma como foi efetivada, por meio tão somente das emendas parlamentares individuais vinculantes, não está acompanhada de uma discussão democrática mais ampla sobre o aperfeiçoamento do modelo. A questão atinge, inclusive, o equilíbrio e a harmonia do sistema constitucional de separação de poderes.

A rigor, muito já se discutia no âmbito do Congresso ${ }^{40}$ sobre formas de refrear os efeitos da flexibilização orçamentária e, sobretudo, restringir a incidência dos tradicionais instrumentos aplicados no presidencialismo de coalizão, demonstrando-se intensa insatisfação parlamentar com o

\footnotetext{
${ }^{39}$ Embora se costume falar em orçamento impositivo no Brasil após o advento da EC n. 86/2015, a reforma constitucional inovou apenas tornando vinculativa a execução orçamentária quanto às emendas parlamentares individuais, e em pequeno percentual, limitadas à $1,2 \%$ da receita líquida corrente do exercício anterior, nos termos do artigo 166, $\S 11$, da $\mathrm{CF} / 88$. Todavia, além dessa imposição, há outras despesas constitucionalmente obrigatórias, o que leva alguns autores a afirmarem que, a rigor, já se teria orçamento impositivo no Brasil.

${ }^{40}$ É possível citar, a título ilustrativo, algumas propostas incluídas em discussão no Congresso, todas referentes ao tema em questão: PEC 385/2005, PEC 96/2007, PEC 46/2007, PEC 574/2006, PEC 550/2006, PEC 20/2011, dentre outras. Ganhou evidência, contudo, a PEC 356/2006, posteriormente convertida na EC 86/2015.
} 
predomínio do Executivo na gestão das finanças públicas, a provocar um desequilíbrio na relação entre os poderes. Uma das possibilidades aventadas, inclusive, era o fim das ditas emendas parlamentares individuais ${ }^{41}$. Mas, ao contrário, visando conferir maior impositividade ao orçamento, optou-se pelo caminho inverso, alterando o texto constitucional para estabelecer a vinculação expressa do Executivo às emendas individuais parlamentares.

Art. 166, $\S 9^{\circ}, \mathrm{CF} / 88$ : As emendas individuais ao projeto de lei orçamentária serão aprovadas no limite de 1,2\% (um inteiro e dois décimos por cento) da receita corrente líquida prevista no projeto encaminhado pelo Poder Executivo, sendo que a metade deste percentual será destinada a ações e serviços públicos de saúde.

Art. 166, $111^{\circ}, \mathrm{CF} / 88$ : É obrigatória a execução orçamentária e financeira das programações a que se refere o $\S 9^{\circ}$ deste artigo, em montante correspondente a 1,2\% (um inteiro e dois décimos por cento) da receita corrente líquida realizada no exercício anterior, conforme os critérios para a execução equitativa da programação definidos na lei complementar prevista no $\S 9^{\circ}$ do art. 165. (BRASIL, 1988).

A partir do novo regime de obrigatoriedade de execução das emendas parlamentares individuais, significativo impacto decorrerá da alteração na prática de contingenciamento de emendas para aprovação de matérias de interesse do Executivo junto ao Parlamento. O orçamento autorizativo fornece vantagem distributiva para membros da coalizão, permitindo que parlamentares pertencentes à base governista tenham emendas orçamentárias individuais executadas. A adoção do orçamento impositivo, na forma como disposta, beneficia os parlamentares da oposi-

\footnotetext{
41 "Nesse contexto, muito se discute sobre o fim das emendas parlamentares de iniciativa individual e a aptidão da medida como forma de limitar o poder do Chefe do Executivo na liberação dos recursos. Com efeito, a supressão se mostraria hábil a evitar a barganha política em troca de votos, na medida em que o interesse na liberação dos recursos voltados às emendas orçamentárias estaria difundido entre os diversos parlamentares. Verifica-se que as propostas não param por ai. Com efeito, além das diversos iniciativas visando à supressão das emendas individuais, vislumbram-se outras, como a de tornar compulsória a execução das emendas, sem falar na proposta de se conferir impositividade ao próprio orçamento." (DALLAVERDE, 2013, p. 172-173)
} 
ção e prejudica os da situação. Sob esse ponto de vista, percebendo a moeda de troca que havia virado o orçamento público no contexto do jogo político, não há dúvidas de que parece ser frutífera a alteração constitucional. Todavia, apenas transferir ao Legislativo parcela do poder decisório na escolha de prioridades para fins de implementação de políticas públicas não necessariamente garante a aplicação dos recursos públicos para o efetivo atendimento das necessidades públicas e concretização dos direitos fundamentais.

Por trás de um discurso que se invoca a pretexto da ineficiência do Executivo, no fundo há uma tensão e forte disputa política entre os poderes para qual deles ficará com maior parcela de competência na destinação dos recursos públicos. A discussão passa longe de se situar onde efetivamente deveria: na visão do orçamento como elemento concretizador dos direitos fundamentais e vinculado aos fins constitucionais. Por que a destinação dada por um parlamentar via emenda individual seria mais benéfica ao povo do que aquela contida na lei orçamentária fruto de intensa discussão e participação popular na sua formulação? Não seria mais válido dotar o orçamento como um todo de maior força vinculante, como era a proposta inicial, independente da origem da destinação ser proveniente do Executivo ou Legislativo, sob pena de ferimento à separação dos poderes? Sobre esse ponto, a propósito, registre-se o apontamento do Min. Luiz Fux em decisão liminar na ADI 4.663 na Suprema Corte:

[...] as normas orçamentárias ostentariam a denominada força vinculante mínima, a ensejar a imposição de um dever prima facie de acatamento, ressalvada motivação administrativa que justificasse o descumprimento com amparo na razoabilidade, fossem essas normas emanadas da proposta do Executivo, fossem fruto de emenda apresentada pelo Legislativo. Assim, a atribuição de regime formal privilegiado exclusivamente às normas oriundas de emendas parlamentares violaria a harmonia entre os poderes políticos. (ADI 4663 Referendo-MC/RO, Rel. Min. Luiz Fux, Dj 07.03.2012)

A nova dinâmica de relação entre os poderes insurge-se na medida em que, agora, o Executivo estará, em certa medida, vinculado ao que determina o Legislativo, nascendo premissas que precisam ser bem avalia- 
das na tensão entre os poderes no âmbito da gestão das finanças públicas. Por outro lado, nem se abordará, embora se reconheça tal risco, a eventual improbidade legislativa em caso de emenda parlamentar manejada para fins eleitorais em detrimento do interesse público. Ou ainda, os impactos na relação entre os poderes que o novo modelo orçamentário vem trazer ao abrir margem para possibilidade de responsabilização ao governante em face de eventual descumprimento das emendas impositivas. $\mathrm{O}$ regime constitucional trazido pela EC n. 86/2015 passa à margem de todas estas discussões, não conferindo segurança jurídica à eficiência do novo modelo que se apresenta.

Por outro lado, a reforma constitucional, ao invés de fortalecer a lei orçamentária, a enfraquece, pois, na medida em que, de forma expressa pelo constituinte, afirma-se que somente a previsão das emendas individuais parlamentares vinculam a sua execução, acaba-se por se concluir, a contrario sensu, que o orçamento continua não sendo obrigatório no seu todo $^{42}$. Não fosse isso, não faria sentido a EC n. 86/2015 dispor sobre força vinculante apenas das emendas parlamentares individuais, caso já se considerasse que o orçamento teria passado a gozar de uma impositividade mínima em todo o seu conteúdo. Aliás, ainda em sede de apreciação da ADI 4.663, chegou o Min. Marco Aurélio a esta mesma constatação:

O Min. Marco Aurélio, por sua vez, referendou a decisão, mas deu interpretação conforme aos preceitos impugnados e assentou que todo o orçamento teria força vinculativa, ao menos mínima. Adu-

\footnotetext{
${ }^{42}$ No mesmo sentido: "Entretanto, a forma como foi promovida a alteração da Constituição, declarando-se explicitamente a obrigatoriedade de execução apenas das programações derivadas de emendas, autoriza a conclusão, quanto às demais programações, que essas teriam caráter apenas autorizativo. Válida essa interpretação, a emenda constitucional do orçamento impositivo, em vez de valorizar o papel da lei orçamentária na definição de todo o conjunto de iniciativas e investimentos públicos, pode estar consagrando o poder discricionário de execução da parcela mais relevante das programações orçamentárias que, juntamente com as emendas, são igualmente aprovadas no Legislativo." (CONGRESSO NACIONAL. Consultoria de Orçamento e Fiscalização Financeira da Câmara dos Deputados; Consultoria de Orçamento, Fiscalização e Controle do Senado Federal. Estudo Técnico Conjunto $n^{\circ}$ 1, de 2015: o Regime do Orçamento Impositivo das Emendas Individuais - Disposições da Emenda Constitucional ${ }^{\circ} 86 / 2015$, e da LDO 2015.
} 
ziu que, quanto às emendas parlamentares, sob o receio da generalização do caráter autorizativo do orçamento, previra-se vinculação. Ocorre que houvera a presunção de desnecessidade de alerta ao Executivo quanto à vinculação, pois ele a observaria. Assim, se o Executivo deixasse de aplicar - em determinada política pública específica prevista no orçamento - certo valor, ele teria de motivá-lo. Sublinhou recear que o STF, ao emprestar vinculação no que se refere às emendas legislativas, mas não quanto ao que encaminhado pelo Executivo, endossaria a natureza simplesmente autorizativa do orçamento. (ADI 4663 Referendo-MC/RO, Rel. Min. Luiz Fux, Dj 07.03.2012, nos termos do Informativo STF n. 657, 2012)

A solução parece estar em uma reforma estrutural que busque dotar de maior impositividade não somente as verbas oriundas das emendas parlamentares individuais vinculantes ${ }^{43}$. Aliás, não se justifica este privilégio individual somente aos parlamentares. Ao contrário, abre-se margem para redutos eleitorais e manipulação de verbas públicas como já aconteceu tempos atrás em rotineiras hipóteses de corrupção envolvendo as rubricas orçamentárias provenientes de emendas parlamentares. Maior garantia haverá, certamente, se todo o planejamento orçamentário, aprovado em decisão colegiada após regular tramitação, passar a gozar de maior efetividade pela imposição do cumprimento de suas disposições. Se a escusa administrativa de cumprimento das emendas vinculantes é facultada em casos excepcionais de impedimentos de ordem técnica, o mesmo raciocínio poderia ser aplicado para o orçamento como um todo, não havendo motivos para manter o sistema diferenciado exclusivamente na parcela orçamentária referente às emendas parlamentares individuais.

\footnotetext{
${ }^{43}$ Destaque-se, nesse ponto, reflexão de Marcus Abraham quanto ao orçamento impositivo no modelo brasileiro: "O tema do orçamento impositivo merece algumas reflexões. Primeiro, se, por um lado, essa ideia retiraria a flexibilidade de que o administrador público necessita para conduzir sua atividade, mormente pela impossibilidade fática de identificar e prever com antecedência todas as despesas públicas, por outro, resgataria a credibilidade e importância do orçamento como documento formal de planejamento do governo, que muitas vezes sofre diante dos recorrentes descumprimentos das suas previsões, chegando a ser considerado de forma pejorativa uma simples "carta de intenções". (ABRAHAM, 2017, p. 328-329)
} 


\section{Conclusão}

Embora se reconheça que o instituto do orçamento público teve grande evolução em tempos recentes, passando de mera peça contábil que regula receitas e despesas para adquirir contornos de instrumento de planejamento programático de governo, com suas regras atualmente dispostas na própria Constituição Federal, percebe-se, todavia, que ainda precisa ser dado mais um passo, no sentido de compreender efetivamente o orçamento público como uma peça fundamental no contemporâneo Estado Constitucional Democrático. Seu objetivo primordial, para além do jogo político e da disputa de poder, insere-se na concretização dos direitos fundamentais e na garantia do princípio democrático. De fato, muito ficou fragilizada a noção do orçamento público a partir do seu histórico desvirtuamento com as manobras de flexibilização governamental e a constante tensão entre os poderes no âmbito de sua gestão.

Dessa feita, apesar de o entendimento majoritário ainda não ter sido expressamente modificado no sentido de ainda se considerar o orçamento público como lei formal de efeitos concretos, inábil a gerar direitos subjetivos e vincular o Estado à sua observância, mudanças nesse paradigma já podem ser notadas, seja pelo atual reconhecimento da possibilidade de controle de constitucionalidade das normas orçamentárias, seja pela atuação judicial em defesa dos direitos fundamentais no âmbito da implementação de políticas públicas, ou ainda, seja pela linha que se observa no Supremo Tribunal Federal a partir da tese levantada na ADI 4.663 no sentido de conferir ao orçamento uma chamada vinculação mínima, acompanhando toda discussão que já há muito tempo se travava na doutrina financista mais contemporânea.

De toda forma, a mudança no texto constitucional decorrente da EC n. 86/2015 ao trazer a previsão das emendas parlamentares vinculantes, inaugurando uma nova sistemática nas relações de poder, parece não ter sido a melhor resposta aos anseios sociais de maior impositivdade da peça orçamentária. Permanece a observação de que o orçamento continua a ser manejado como instrumento de governo e não como fundamental elemento democrático para a concretização das garantias fundamentais e consecução dos fins do Estado. A mudança constitucional, muito mais 
política do que jurídica, passa ao largo de atingir a real problemática que circunda a gestão das finanças no Brasil. E mais, com a alteração produzida pela EC 86/2015, é de se verificar que, na contramão dos recentes pronunciamentos no âmbito da Suprema Corte, acabou sendo reforçado o caráter autorizativo do orçamento no seu todo, vinculando-se tão somente a execução provenientes das emendas parlamentares individuais.

Apesar do orçamento ser peça chave para a nação, na prática as suas disposições convertem-se em mera promessa, expectativas que muitas vezes não saem do papel. Tal panorama não será alterado pelo simples ingresso das emendas parlamentares vinculantes. Ao contrário, por vias transversas buscou-se realizar uma reforma que traz mais insegurança e menos transparência do que dotar todo o orçamento público de maior impositividade. $\mathrm{O}$ caráter autorizativo abre margem ao mau gestor para a realização de práticas no campo da discricionariedade administrativa que vão de encontro aos reais objetivos orçamentários. Com isso, as expectativas criadas a partir da proposta orçamentária não demoram muito para serem frutadas logo em seguida, convertendo-se o orçamento em mera peça retórica. Por isso é que se torna inevitável revigorar a discussão com a coragem necessária para levantar o debate acerca do modelo impositivo orçamentário com a devida responsabilidade, não o fazendo apenas como rearranjo político, da forma que tem sido historicamente tratado no Brasil.

\section{Referências}

ABRAHAM, Marcus. Curso de Direito Financeiro Brasileiro. 4. ed. São Paulo: Forense, 2017.

. Efetividade e vinculação das leis orçamentárias e a ADI n.

4.663. In: GOMES, Marcus; ABRAHAM, Marcus; TORRES, Heleno Taveira (Coord.). Direito financeiro na jurisprudência do Supremo Tribunal Federal: homenagem ao ministro Marco Aurélio. Curitiba: Juruá, 2016.

ASSONI FILHO, Sergio. Transparência fiscal e democracia. Porto Alegre: Nuria Fabris, 2009. 


\section{BARCELlOS, Ana Paula de. A Eficácia Jurídica dos Princípios}

Constitucionais. Rio de Janeiro: Renovar, 2002.

. Neoconstitucionalismo, direitos fundamentais e controle das políticas públicas. Revista de Direito Administrativo, [S.l.], v. 240, p. 83-105, 2005.

BARROSO. Neoconstitucionalismo e constitucionalização do direito: o triunfo tardio do direito constitucional no Brasil. Revista da EMERJ, [S.l.], v. 9, n. 33, 2006.

BINENBOJIM, Gustavo. Uma teoria do direito administrativo: direitos fundamentais, democracia e constitucionalização. 3. ed. Rio de Janeiro: Renovar, 2014.

BUJANDA, F. Sainz de. Hacienda y Derecho: Introdução ao Estudo Político. Madrid: [s.n.], 1955.

CARVALHO PINTO, Carlos Alberto A. Normas Gerais de Direito Financeiro. São Paulo: Prefeitura de São Paulo, 1949.

DALLAVERDE, Alexsandra Katia. As relações entre os poderes na gestão das finanças públicas. Porto Alegre: Nuria Fabris, 2013.

EINAUDI, Luigi. Principios de Hacienda Publica. Trad. J. Alcarra e Miguel Paredes. Madrid. Aguillar. 1948.

FERRAJOLI, Luigi. A democracia através dos direitos: o constitucionalismo garantista como modelo teórico e como projeto político. São Paulo: Revista dos Tribunais, 2015.

FOUNROUGE, Carlos M. Giuliani. Derecho financeiro. 2. ed. Buenos Aires: Depalma, 2001.

FREITAS, Juarez. O direito fundamental à boa administração pública. São Paulo: Malheiros, 2014.

FUX, Luiz. Orçamento público na jurisprudência do STF: a possibilidade de controle judicial, a autonomia constitucional orçamentária e a problemática do orçamento participativo. In: GOMES, Marcus; ABRAHAM, Marcus; TORRES, Heleno Taveira (Coord.). Direito 
financeiro na jurisprudência do Supremo Tribunal Federal: homenagem ao ministro Marco Aurélio. Curitiba: Juruá, 2016.

MENDONÇA, Eduardo Bastos de. A constitucionalização das finanças públicas no Brasil: devido processo orçamentário e democracia. Rio de Janeiro: Renovar, 2010.

OLIVEIRA, Regis Fernandes de. Curso de Direito Financeiro. 4. ed. São Paulo: Revista dos Tribunais, 2011.

SARLET, Ingo Wolfgang. A eficácia dos direitos fundamentais: uma teoria geral dos direitos fundamentais na perspectiva constitucional. 12. ed. Porto Alegra: Livraria do Advogado, 2015.

SARMENTO, Daniel. Ubiquidade constitucional: os dois lados da moeda. Revista de Direito do Estado, [S.l.], n. 2, p. 83-118, 2006.

SOUZA, Rubens Gomes de. Normas Gerais de Direito Financeiro. Revista Forense, [S.l.], v. 155. p. 21-35, 1954.

TORRES, Heleno Taveira. Direito constitucional financeiro: teoria da constituição financeira. São Paulo: Revista dos Tribunais, 2014.

TORRES, Ricardo Lobo. Tratado de Direito Constitucional Financeiro e Tributário: orçamento na Constituição. 3. ed. Rio de Janeiro: Renovar, 2008, v. 5.

Cláudio Ladeira de Oliveira é doutor e mestre em Direito pela Universidade Federal de Santa Catarina (UFSC) com estágio de doutoramento na Universidade de Lisboa, graduado em Direito pela Universidade Federal de Mato Grosso (UFMG) e professor de Direito da Universidade Federal de Santa Catarina (UFSC).

E-mail: claudioladeira@hotmail.com.

Endereço Profissional: Universidade Federal de Santa Catarina, Centro de Ciências Jurídicas, Trindade, Florianópolis, SC. CEP: 88040-900. 
Francisco Gilney Bezerra de Carvalho Ferreira é mestrando em Direito pela Universidade Federal de Santa Catarina (UFSC) e graduado em Direito (UNIFOR) e Engenharia Civil (UFC). Possui especialização em direito público e MBA em gestão pública (FGV). É também Procurador Federal (AGU) e professor de Direito da Faculdade Luciano Feijão (Sobral/CE).

E-mail: gilneybezerra@hotmail.com.

Endereço Profissional: Advocacia-Geral da União, Procuradoria Seccional Federal em Sobral, Derby, Sobral, CE. CEP: 62040-730. 